\title{
Avaliação do modelo CNCPS na predição do consumo de matéria seca em vacas da raça Holandesa em pastejo ${ }^{1}$
}

\section{Ana Cristina Wyllie Elyas ${ }^{2}$, Paulo César de Aguiar Paiva ${ }^{3}$, Fernando César Ferraz Lopes ${ }^{4}$, Duarte Vilela ${ }^{4}$, Pedro Braga Arcuri ${ }^{4}$, Mirton José Frota Morenz ${ }^{5}$}

\author{
1 Pesquisa financiada parcialmente pela FAPEMIG e pelo CNPq. \\ 2 Programa de Pós-graduação em Zootecnia - UFLA. \\ 3 DZO-UFLA Cx. Postal 37 - CEP: 37.200-000 - Lavras, MG. \\ 4 Embrapa Gado de Leite. Rua Eugênio do Nascimento 610. Bairro Dom Bosco - CEP: 36038-330 - Juiz de Fora, MG. \\ ${ }^{5}$ DNAP-IZ-UFRRJ. Rod. BR 465, km 07, Seropédica, RJ - CEP: 23890-000.
}

RESUMO - Este trabalho foi realizado com o objetivo de avaliar o modelo Cornell Net Carbohydrate and Protein System (CNCPS), versão 5.0, na predição do consumo de matéria seca de vacas da raça Holandesa, lactantes, em pastagem de capim coast-cross suplementada com silagem de milho e concentrado ( $3 \mathrm{ou} 6 \mathrm{~kg} / \mathrm{vaca}$.dia). Foram realizados seis ensaios experimentais, cada um com 12 vacas. Em três das avaliações, os animais receberam, além do concentrado, $17 \mathrm{~kg}$ de silagem de milho/dia (base natural). As coletas de forragem selecionada na pastagem para análise da composição química foram realizadas por uma vaca com fístula esofágica. A estimativa do consumo voluntário foi realizada com sesquióxido de cromo $\left(\mathrm{Cr}_{2} \mathrm{O}_{3}\right)$, administrado em doses de $5 \mathrm{~g}$, duas vezes ao dia. Foram fornecidos ao programa dados (inputs) referentes aos animais (peso vivo corporal, escore corporal, idade, produção e composição do leite e tipo racial), ao ambiente (temperatura, umidade relativa do ar e manejo) e à composição do alimento em cada período experimental. Os valores preditos pelo CNCPS para a ingestão voluntária de matéria seca foram próximos àqueles estimados, havendo pequena tendência do modelo em subestimar o valor determinado com o indicador.

Palavras-chave: ingestão de matéria seca, modelos de predição, sistema de pastejo, vacas em lactação

\section{Evaluation of the Cornell Net Carbohydrate and Protein System on the prediction of dry matter intake of grazing lactating Holstein cows}

ABSTRACT - The aim of this work was to evaluate the ability of the Cornell Net Carbohydrate and Protein System (CNCPS) version 5.0 to estimate the dry matter intake (DMI) of grazing lactating Holstein cows, grazing coast-cross pasture supplemented with corn silage and concentrate (3 or $6 \mathrm{~kg} / \mathrm{cow} / \mathrm{day})$. Six experiments were carried out, with 12 cows each. The cows were fed $17 \mathrm{~kg} / \mathrm{cow} /$ day of corn ensilage in three experiments. The chemical composition of extrusa samples of forage was determined, obtained using an esophageous fistulated cow. The intake estimates were obtained using $5 \mathrm{~g}$ of chromium oxide $\left(\mathrm{Cr}_{2} \mathrm{O}_{3}\right)$ methodology supplied two times a day. Data corresponding to animals (body weight, age, milk yield and composition and racial type), environment (temperature, air relative humidity and management condition) and the feed chemical composition in each experimental period were provided to the program. The DMI values predicted by the CNCPS model were close to those obtained by the chromium oxide methodology.

Key Words: dry matter intake, grazing systems, lactating cows, prediction models

\section{Introdução}

Nos sistemas em que animais de alta produtividade são manejados em pastejo, é fundamental recorrer à suplementação, cuja importância depende do potencial de produção leiteira e da fase de lactação em que se encontra o animal (Alvim et al., 1999). A alta correlação da ingestão de matéria seca (MS) com a digestibilidade do alimento, as características de fermentação e a taxa de passagem
(Meissner \& Paulsmeier, 1995) requer entendimento do efeito do suplemento protéico-energético sobre o desempenho do animal para formular estratégias adequadas de suplementação do pasto.

Segundo Mertens (1992), a ingestão voluntária de matéria seca pode ser influenciada pelas características do animal, do alimento e das condições de alimentação. Assim, o uso de modelos de predição para animais em pastejo é de grande importância, pois auxilia na formulação 
de concentrados visando aumentar a produção (Genro et al., 2004).

O Cornell Net Carbohydrate and Protein System (CNCPS) é um modelo matemático desenvolvido para avaliação de dieta e predição do desempenho do rebanho a partir dos princípios básicos de função ruminal, crescimento microbiano, fisiologia animal, digestão e fluxo dos alimentos. Esse sistema inclui ainda características de manejo, condições climáticas e a caracterização dos alimentos e dos animais (Fox et al., 2004). O modelo é capaz de predizer o consumo de matéria seca para diversas categorias de animais utilizando equações de ajuste para bovinos consumindo acima do nível de mantença (Fox et al., 2004). No entanto, o CNCPS foi desenvolvido com base em sistemas de produção característicos de regiões de clima temperado, com alimentos e padrão racial dos animais diferentes dos utilizados no Brasil. A última versão do modelo CNCPS (versão 5.0) possui um banco de dados sobre alimentos tropicais atualizado e expandido, o que, teoricamente, permite melhor ajuste nas predições do desempenho em sistemas de produção de bovinos em condições tropicais. Entretanto, mesmo com a inclusão desse banco de dados e a possibilidade de atualização dos dados, a aplicação do modelo em condições tropicais deve ser avaliada.

O objetivo neste trabalho foi avaliar o modelo CNCPS, versão 5.0, na predição do consumo de MS de vacas da raça Holandesa em pastagem de capim coast-cross suplementada com silagem de milho e concentrado (3 ou $6 \mathrm{~kg} /$ animal.dia).

\section{Material e Métodos}

$\mathrm{O}$ experimento foi realizado no período de janeiro a novembro de 2003. O clima, segundo a classificação de Köppen, é o Cwa, definido como seco no inverno e chuvoso no verão (Tabela 1 ).

A área experimental foi constituída de 160 piquetes, divididos por cerca elétrica, com área unitária de $475 \mathrm{~m}^{2} \mathrm{de}$ capim coast-cross (Cynodon dactylon (L) Pers), dispostos em delineamento inteiramente casualizado, com quatro repetições. Os piquetes foram pastejados em sistema rotacionado, com 18 dias de descanso no período chuvoso e 39 dias de descanso no período seco, com taxa de lotação de 5,8 UA/ha.

A adubação de manutenção foi realizada com nitrogênio (200 kg/ha.ano), $\mathrm{P}_{2} \mathrm{O}_{5}$ ( $80 \mathrm{~kg} / \mathrm{ha}$.ano) e $\mathrm{K}_{2} \mathrm{O}$ ( $160 \mathrm{~kg} / \mathrm{ha}$.ano), distribuídos em seis aplicações a cada dois meses. Após as adubações de manutenção e nos meses de menor precipitação (entre 12 de maio e 2 outubro), a pastagem foi irrigada
Tabela 1 - Descrição das variáveis utilizadas na predição do consumo de matéria seca de vacas da raça Holandesa, utilizando-se o modelo CNCPS

\begin{tabular}{|c|c|c|c|}
\hline \multirow[t]{2}{*}{ Descrição } & \multicolumn{3}{|c|}{ Período experimental } \\
\hline & Janeiro & Março & Maio \\
\hline Velocidade do vento (kph) & 0,9 & 0,9 & 0,9 \\
\hline $\begin{array}{l}\text { Temperatura do mês } \\
\text { anterior }\left({ }^{\circ} \mathrm{C}\right)\end{array}$ & 24,6 & 24,6 & 21,9 \\
\hline $\begin{array}{l}\text { Temperatura do } \\
\text { mês atual }\left({ }^{\circ} \mathrm{C}\right)\end{array}$ & 24,3 & 22,3 & 18,6 \\
\hline Temperatura mínima $\left({ }^{\circ} \mathrm{C}\right)$ & 20,4 & 19,4 & 12,6 \\
\hline $\begin{array}{l}\text { Umidade relativa do } \\
\text { mês anterior }(\%)\end{array}$ & 80 & 73 & 80 \\
\hline $\begin{array}{l}\text { Umidade relativa } \\
\text { do mês atual }(\%)\end{array}$ & 83 & 78 & 80 \\
\hline Animal ofegante & Não & Não & Não \\
\hline Tipo de sistema & & tejo inten & vo \\
\hline \multirow[t]{2}{*}{ Descrição } & \multicolumn{3}{|c|}{ Período experimental } \\
\hline & Julho & Setembro & Novembro \\
\hline Velocidade do vento (kph) & 1,2 & 1,5 & 1,3 \\
\hline $\begin{array}{l}\text { Temperatura do mês } \\
\text { anterior }\left({ }^{\circ} \mathrm{C}\right)\end{array}$ & 18 & 16,7 & 21,1 \\
\hline $\begin{array}{l}\text { Temperatura do } \\
\text { mês atual }\left({ }^{\circ} \mathrm{C}\right)\end{array}$ & 16,7 & 19,7 & 22,7 \\
\hline Temperatura mínima $\left({ }^{\circ} \mathrm{C}\right)$ & 9,8 & 14,4 & 18,2 \\
\hline $\begin{array}{l}\text { Umidade relativa do } \\
\text { mês anterior }(\%)\end{array}$ & 76 & 75 & 77 \\
\hline $\begin{array}{l}\text { Umidade relativa } \\
\text { do mês atual }(\%)\end{array}$ & 76 & 75 & 77 \\
\hline Animal ofegante & Não & Não & Não \\
\hline Tipo de sistema & \multicolumn{3}{|c|}{ Pastejo intensivo } \\
\hline
\end{tabular}

por aspersão utilizando-se 15 aspersores com vazão individual de 4,0 $\mathrm{m}^{3}$ /hora. O intervalo das irrigações era avaliado por tensiômetros de cápsulas porosas a fim de manter o solo com 60 a $65 \%$ de umidade.

Foi avaliado o modelo CNCPS, versão 5.0 (nível 2), na predição do consumo de MS. O nível 2 do modelo CNCPS inclui os efeitos da fermentação ruminal e realiza as predições com base no submodelo do rúmen. Foram fornecidas ao programa informações referentes aos animais, ao ambiente e à composição dos alimentos em cada período experimental.

Na predição do consumo de matéria seca, foi utilizada a equação de Milligan et al. (1981) para vacas da raça Holandesa. Realizaram-se seis ensaios experimentais para avaliação do modelo. Em cada ensaio, foram utilizadas 12 vacas da raça Holandesa Preto e Branco (seis em cada tratamento), puras de origem, prenhes e vazias, em diferentes estádios de lactação e produzindo entre 11,13 e 28,50 kg de leite/vaca.dia, recebendo concentrado na quantidade de 3 ou $6 \mathrm{~kg} /$ vaca.dia (Tabelas 2 e 3 ). O concentrado era composto de $62 \%$ de milho moído, $35 \%$ de soja integral tostada, $1 \%$ de bicarbonato de sódio, $1 \%$ de calcário calcítico e $1 \%$ de mistura mineral (Tabelas 4 e 5), divididos 
em duas ofertas diárias, durante as ordenhas. Nas avaliações com início em 10/1, 22/3 e 24/11 de 2003, os animais receberam apenas concentrado como suplemento. Nos períodos de 24/5, 27/7 e 23/9 de 2003, os animais receberam, além do concentrado, $17 \mathrm{~kg} / \mathrm{vaca}$.dia de silagem de milho (base na matéria natural).

Tabela 2 - Descrição das variáveis utilizadas na predição do consumo de matéria seca de vacas da raça Holandesa em pastagem de capim coast-cross suplementada com concentrado

\begin{tabular}{|c|c|c|c|c|}
\hline \multirow[t]{2}{*}{ Variável } & \multicolumn{2}{|c|}{$\begin{array}{c}3 \mathrm{~kg} \mathrm{de} \\
\text { concentrado/dia }\end{array}$} & \multicolumn{2}{|c|}{$\begin{array}{c}6 \mathrm{~kg} \mathrm{de} \\
\text { concentrado/dia }\end{array}$} \\
\hline & Média & $\begin{array}{l}\text { Desvio- } \\
\text { padrão }\end{array}$ & Média & $\begin{array}{l}\text { Desvio- } \\
\text { padrão }\end{array}$ \\
\hline Idade (meses) & 68,77 & 14,68 & 65,33 & 18,04 \\
\hline Peso vivo $(\mathrm{kg})$ & 547,00 & 43,30 & 582,00 & 74,12 \\
\hline Dias em gestação & 49,58 & 68,49 & 65,07 & 92,63 \\
\hline Número da lactação & 3,00 & 1,17 & 3,28 & 2,16 \\
\hline Dias em lactação & 208,64 & 113,97 & 231,60 & 118,45 \\
\hline $\begin{array}{l}\text { Intervalo de } \\
\text { partos (meses) }\end{array}$ & 446,00 & 168,02 & 311,35 & 188,93 \\
\hline $\begin{array}{l}\text { Idade ao primeiro } \\
\text { parto (meses) }\end{array}$ & 33,47 & 8,02 & 31,92 & 3,97 \\
\hline $\begin{array}{l}\text { Produção de leite } \\
(\mathrm{kg} / \text { vaca×dia) }\end{array}$ & 15,16 & 4,03 & 16,72 & 4,79 \\
\hline Gordura no leite (\%) & 3,14 & 0,49 & 3,09 & 0,52 \\
\hline Proteína no leite (\%) & 2,76 & 0,18 & 2,96 & 0,10 \\
\hline $\begin{array}{l}\text { Escore de condição } \\
\text { corporal }\end{array}$ & 2,94 & 0,23 & 3,05 & 0,41 \\
\hline $\begin{array}{l}\text { Consumo de MS } \\
\left(\mathrm{Cr}_{2} \mathrm{O}_{3}\right)\end{array}$ & 2,47 & 0,25 & 2,64 & 0,57 \\
\hline
\end{tabular}

Os animais foram mantidos em pasto, com acesso a água e sombra (sombrite). As vacas foram ordenhadas duas vezes ao dia (às 6 h e 13h30), quando recebiam o concentrado dividido em duas ofertas diárias. Neste período os animais também tinham acesso a sal mineral comercial.

Tabela 3 - Descrição das variáveis utilizadas na predição do consumo de matéria seca de vacas da raça Holandesa em pastagem de capim coast-cross suplementada com concentrado e silagem de milho

\begin{tabular}{|c|c|c|c|c|}
\hline \multirow[t]{2}{*}{ Variável } & \multicolumn{2}{|c|}{$\begin{array}{c}3 \mathrm{~kg} \mathrm{de} \\
\text { concentrado/dia }+ \\
\text { silagem de milho }\end{array}$} & \multicolumn{2}{|c|}{$\begin{array}{c}6 \mathrm{~kg} \mathrm{de} \\
\text { concentrado/dia }+ \\
\text { silagem de milho }\end{array}$} \\
\hline & Média & $\begin{array}{l}\text { Desvio- } \\
\text { padrão }\end{array}$ & Média & $\begin{array}{l}\text { Desvio- } \\
\text { padrão }\end{array}$ \\
\hline Idade (meses) & 62,44 & 13,67 & 65,77 & 17,49 \\
\hline Peso vivo $(\mathrm{kg})$ & 554,00 & 48,00 & 606,05 & 55,26 \\
\hline Dias em gestação & 10,37 & 27,49 & 32,26 & 49,24 \\
\hline Número da lactação & 3,12 & 0,95 & 3,93 & 1,75 \\
\hline Dias em lactação & 120,37 & 72,39 & 152,05 & 73,70 \\
\hline $\begin{array}{l}\text { Intervalo de partos } \\
\text { (meses) }\end{array}$ & 446,93 & 105,24 & 349,46 & 141,50 \\
\hline $\begin{array}{l}\text { Idade ao primeiro } \\
\text { parto (meses) }\end{array}$ & 32,50 & 8,46 & 30,73 & 1,43 \\
\hline $\begin{array}{l}\text { Produção de leite } \\
\text { (kg/vaca/dia) }\end{array}$ & 19,44 & 4,28 & 23,22 & 5,28 \\
\hline Gordura no leite $(\%)$ & 3,43 & 0,62 & 3,41 & 1,76 \\
\hline Proteína no leite (\%) & 2,87 & 0,34 & 3,05 & 0,42 \\
\hline $\begin{array}{l}\text { Escore de condição } \\
\text { corporal }\end{array}$ & 3,22 & 0,52 & 3,27 & 0,46 \\
\hline $\begin{array}{l}\text { Consumo de } \mathrm{MS} \\
\left(\mathrm{Cr}_{2} \mathrm{O}_{3}\right)\end{array}$ & 3,13 & 0,41 & 3,24 & 0,46 \\
\hline
\end{tabular}

Tabela 4 - Composição química e taxas de digestão dos nutrientes do capim coast-cross em cada mês de avaliação

\begin{tabular}{|c|c|c|c|c|c|c|}
\hline Composição & Janeiro & Março & Maio & Julho & Setembro & Novembro \\
\hline Proteína bruta (\%MS) & 16,34 & 16,47 & 17,11 & 14,33 & 16,58 & 16,71 \\
\hline Extrato etéreo (\%MS) & 1,23 & 1,59 & 1,31 & 1,21 & 1,04 & 1,15 \\
\hline Fibra em detergente neutro ${ }^{1}(\% \mathrm{MS})$ & 63,77 & 62,09 & 71,45 & 68,25 & 65,60 & 61,79 \\
\hline Fibra em detergente ácido ${ }^{2}(\% \mathrm{MS})$ & 31,16 & 30,02 & 29,19 & 35,15 & 34,64 & 35,43 \\
\hline Lignina $(\% \mathrm{MS})$ & 6,81 & 7,88 & 7,21 & 7,75 & 7,37 & 7,08 \\
\hline Cinzas (\%MS) & 6,70 & 6,72 & 6,87 & 6,80 & 6,78 & 6,80 \\
\hline Carboidratos totais (\%MS) & 75,73 & 75,53 & 75,02 & 77,78 & 75,75 & 75,64 \\
\hline Carboidratos não-fibrosos $\left(\mathrm{A}+\mathrm{B}_{1}\right)(\% \mathrm{MS})$ & 17,04 & 18,36 & 9,01 & 14,83 & 16,65 & 20,84 \\
\hline Carboidratos $\mathrm{B}_{2}(\% \mathrm{MS})$ & 42,25 & 38,28 & 49,06 & 44,42 & 41,48 & 37,87 \\
\hline Carboidratos $\mathrm{C}^{2}(\% \mathrm{MS})$ & 16,44 & 18,92 & 16,95 & 18,54 & 17,62 & 16,93 \\
\hline \multicolumn{7}{|l|}{ Frações nitrogenadas (\% proteína bruta) } \\
\hline A & 32,74 & 26,01 & 23,44 & 23,18 & 31,66 & 29,08 \\
\hline $\mathrm{B}_{1}+\mathrm{B}_{2}$ & 35,86 & 43,89 & 44,56 & 39,92 & 34,59 & 28,24 \\
\hline $\mathrm{B}_{3}$ & 21,10 & 21,69 & 23,57 & 28,24 & 28,76 & 31,83 \\
\hline $\mathrm{C}$ & 10,33 & 8,39 & 8,44 & 8,64 & 11,31 & 10,83 \\
\hline
\end{tabular}

Taxas de digestão (\%/hora)

\begin{tabular}{|c|c|c|c|}
\hline \multicolumn{2}{|c|}{ Carboidratos } & \multicolumn{2}{|c|}{ Proteína } \\
\hline A & $13,20^{1}$ & $\mathrm{~B}_{1}^{2}$ & 135,00 \\
\hline $\mathrm{B}_{1}$ & $13,20^{1}$ & $\mathrm{~B}_{2}{ }^{2}$ & 11,00 \\
\hline $\mathrm{B}_{2}$ & $3,8^{1}$ & $\mathrm{~B}_{3}{ }^{1}$ & 5,20 \\
\hline
\end{tabular}

${ }^{1}$ Lagunes et al. (1999); ${ }^{2}$ Tedeschi et al. (2002). 
Tabela 5 - Composição química das frações nitrogenadas e de carboidratos e taxas de digestão do concentrado e da silagem de milho

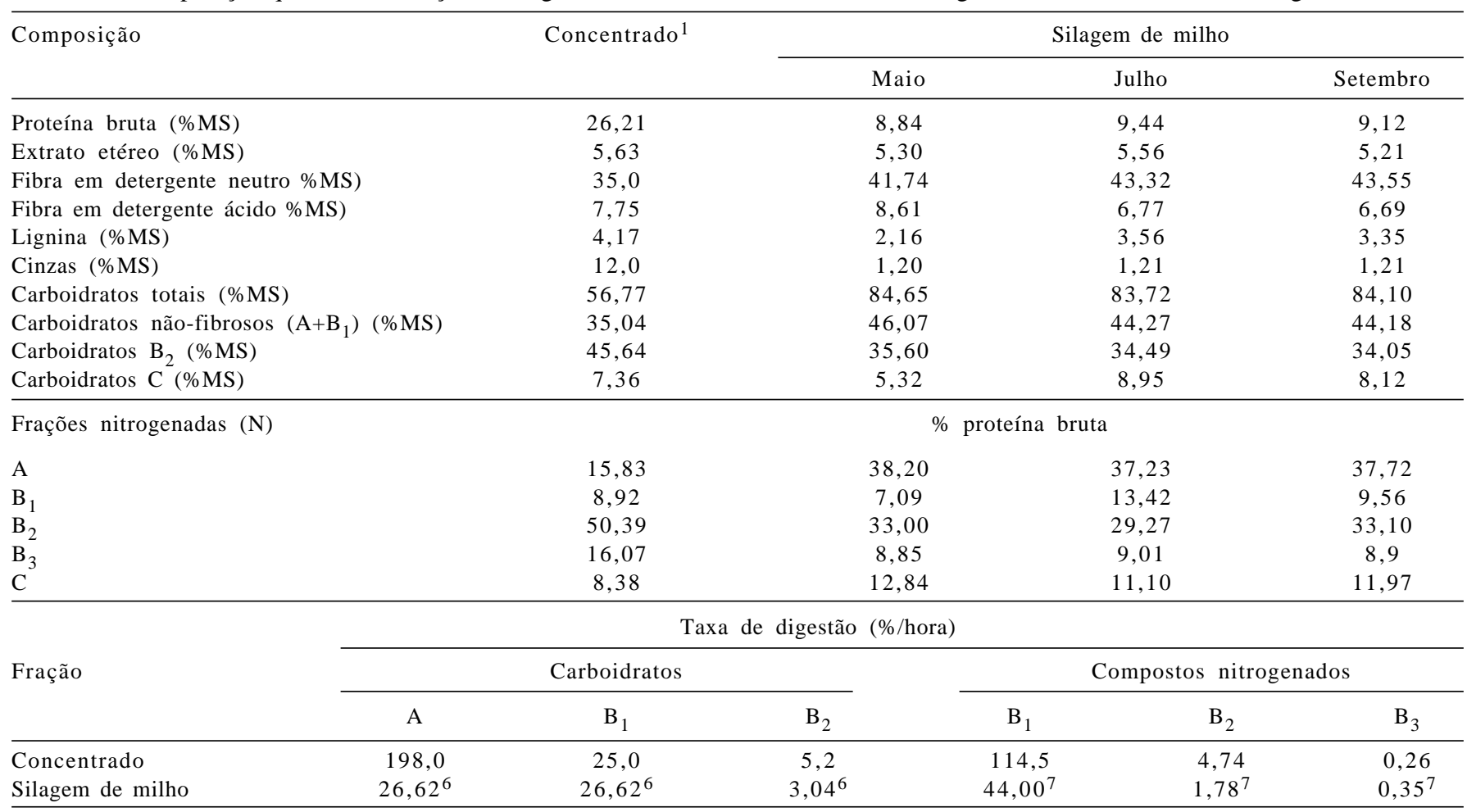

${ }^{1}$ Valores calculados a partir da composição do milho moído e do farelo de soja descrita na biblioteca de forrageiras tropicais do CNCPS, versão 5.0

2 Tedeschi et al. (2002).

${ }^{3}$ Silagem de milho com $30 \%$ de grãos (Cabral et al., 2002).

Os seis ensaios para a estimativa do consumo de MS tiveram duração de 10 dias: os cincos primeiros de adaptação e os demais, de colheita de fezes. Os animais receberam $10 \mathrm{~g}$ de sesquióxido de cromo $\left(\mathrm{Cr}_{2} \mathrm{O}_{3}\right)$, administrado em doses de $5 \mathrm{~g}$, duas vezes ao dia (7h30 e 14h30), sempre após as ordenhas. $\mathrm{O}_{2} \mathrm{Cr}_{3}$ foi embalado em papel-toalha e administrado via oral, com o auxílio de um lança-bolos. As coletas de fezes foram realizadas diretamente no reto dos animais, duas vezes ao dia (7h30 e 14h30), após administração do indicador.

Imediatamente depois de cada coleta, as amostras de fezes foram identificadas e congeladas em temperatura de aproximadamente $-18^{\circ} \mathrm{C}$. Ao final de cada período experimental, foram pré-secas em estufa de ventilação forçada $\left(60 \pm 5^{\circ} \mathrm{C} ; 72\right.$ horas $)$ e moídas com peneira com perfurações de $1 \mathrm{~mm}$. Para determinação da concentração de cromo e do teor de MS, foram utilizadas amostras compostas dos períodos da manhã e da tarde, em cada animal, para cada período.

As amostras individuais de cada dia de pastejo foram submetidas à digestão com ácido nitro-perclórico, segundo método proposto por Kimura \& Miller (1957), e analisadas por espectrofotometria de absorção atômica, utilizando a técnica descrita por Williams et al. (1962). A digestibilidade in vitro da matéria seca (DIVMS) foi obtida de acordo com Tilley \& Terry (1963).

As produções de matéria seca fecal e os consumos da matéria seca da forragem, do concentrado e da silagem foram calculadas adaptando-se a equação de Pond et al. (1989):

Produção fecal = cromo fornecido/cromo na MS fecal (ppm); Consumo $=[($ produção fecal - produção fecal do suplemento)/(100-DIVMS da extrusa) $] \times 100$ (kg MS/dia).

Para a amostragem do pasto consumido e posterior avaliação da composição química, utilizou-se uma vaca mestiça, não-lactante, fistulada no esôfago, equipada com bolsa coletora de lona sintética de fundo telado, ajustada abaixo da fístula, para auxiliar a drenagem da saliva. $\mathrm{O}$ animal foi submetido a jejum prévio de 12 horas para evitar problemas de contaminação com o material regurgitado durante a coleta. Após este período, pela manhã, a vaca foi conduzida à área experimental, onde pastejou livremente por aproximadamente 30 minutos nos piquetes referentes a cada repetição de área, antes de serem pastejados pelas demais vacas.

As coletas de extrusa foram realizadas durante cinco dias: a primeira no dia anterior ao início da coleta de fezes para avaliação do consumo de MS e a última, um dia antes 
do término da coleta de fezes, utilizando-se um total de cinco piquetes. Esse material foi analisado e, a partir dos resultados, foi calculado o valor médio representativo do período em que foi realizada a estimativa do consumo.

Foram coletadas amostras do concentrado para análise e, nos meses de maio, julho e setembro, foram realizadas amostragens da silagem de milho oferecida aos animais. A determinação da composição química foi realizada no Laboratório de Análises de Alimentos - LAA, da Embrapa Gado de Leite (Juiz de Fora, Minas Gerais).

Imediatamente após a coleta, as amostras de extrusa e de silagem de milho foram congeladas em câmara fria a $-18^{\circ} \mathrm{C}$. Após o descongelamento, as amostras foram présecas em estufa de ventilação forçada $\left(60 \pm 5^{\circ} \mathrm{C} ; 72\right.$ horas $)$ e moídas com peneira com perfurações de $1 \mathrm{~mm}$. As amostras de extrusa, silagem e concentrado foram analisadas quanto aos teores de matéria seca (MS), proteína bruta (PB) e extrato etéreo (EE), segundo a AOAC (1990); fibra em detergente neutro (FDN), fibra em detergente ácido (FDA) e lignina, segundo Van Soest et al. (1991).

O fracionamento dos compostos nitrogenados foi realizado de acordo com metodologia descrita por Malafaia \& Vieira (1997). Todas as análises de nitrogênio foram realizadas pelo método de Kjeldahl (AOAC, 1990) e, para conversão em PB, foi utilizado o fator de correção 6,25.

Os carboidratos totais (CT) e as frações de carboidratos correspondentes aos carboidratos não-fibrosos, à fração B2 e à fração C foram calculados de acordo com Sniffen et al. (1992).

Para a avaliação do CNCPS, foram comparados os valores preditos pelo modelo com aqueles estimados (consumo de MS), conforme metodologia descrita por Tedeschi et al. (2000). A acurácia do modelo na predição dos parâmetros foi avaliada utilizando-se o desvio médio (DM) (Cochran \& Cox, 1968) e a raiz do quadrado médio do erro da predição (RQMEP) (Bibby \& Toutenburg, 1997, citados por Molina et al., 2004; Tedeschi et al., 2000; Tedeschi, 2006), que foram calculados da seguinte forma: $\mathrm{DM}=$

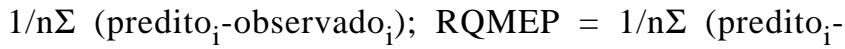
observado $\left.{ }_{i}\right)^{2}$.

$\mathrm{Na}$ análise do desempenho do modelo, foi utilizada a regressão entre os valores estimados (variável-Y) e os valores preditos pelo modelo CNCPS (variável-X). Quando o coeficiente linear ou intercepto $\left(\mathrm{B}_{0}\right)$ não diferiu estatisticamente de "zero" na equação de regressão regular, foi realizada a análise de regressão passando pela origem, em que o intercepto é ajustado para ser igual a "zero" $(\mathrm{P}<0,05)$, estimando-se (parametrizado) apenas o coeficiente angular, obtido quando feita a passagem pela origem $\left(\mathrm{B}_{0}=0\right)$, em que menos 1 é a tendência do modelo em sub ou superpredizer o parâmetro observado. No entanto, quando o intercepto $\left(\mathrm{B}_{0}\right)$ da regressão regular diferiu de "zero" $(\mathrm{P}<0,05)$, a tendência do modelo foi calculada por meio da divisão da diferença das médias da variável $\mathrm{Y}$ e $\mathrm{X}$, pela média da variável $\mathrm{X}$. O uso do $\mathrm{R}^{2}$ para fins de avaliação do modelo não é recomendado nesses casos (Tedeschi et al., 2000).

As análises foram realizadas utilizando-se o programa estatístico SAS (1991). Os parâmetros das regressões regulares foram obtidos utilizando-se o procedimento PROC REG. Para regressões passando pela origem, executou-se o comando "NOINT" no procedimento PROC REG. Os desvios médios (DM) e os parâmetros das equações de regressão foram testados utilizando-se o teste t a $5 \%$ de probabilidade.

\section{Resultados e Discussão}

O desvio médio (DM) obtido entre os valores preditos pelo modelo e estimados pelo $\mathrm{Cr}_{2} \mathrm{O}_{3}$ /DIVMS não diferiu $(\mathrm{P}>0,05)$ pelo teste $\mathrm{t}$ (Tabela 6$)$. A proximidade dos valores médios, predito e estimado, indica a acuidade do modelo. Entretanto, o CNCPS foi pouco preciso na predição desta variável, pois ora subestimou ora superestimou os valores obtidos como $\mathrm{Cr}_{2} \mathrm{O}_{3}$ /DIVMS (Figura 1A). Segundo Tedeschi et. al. (2004) e Morenz (2004), para um ajuste perfeito, o modelo deve apresentar duas características: acuidade e precisão. No entanto, ambas são medidas de forma independente e um método preciso não garante a acuidade, e viceversa. De acordo com Tedeschi (2006), a acuidade ou exatidão pode ser considerada a mais importante, uma vez que mede a habilidade do modelo em predizer valores reais.

O consumo de MS estimado para os animais alimentados com $6 \mathrm{~kg} /$ dia de concentrado, obtido pela metodologia do $\mathrm{Cr}_{2} \mathrm{O}_{3}$ /DIVMS, não diferiu $(\mathrm{P}<0,05)$ do predito pelo modelo. O baixo valor observado para o desvio médio indica que o modelo foi capaz de estimar o consumo voluntário com exatidão (Tabela 6). Foi realizada a análise de regressão passando pela origem, na qual o intercepto foi ajustado para ser igual a "zero" $(\mathrm{P}>0,05)$, uma vez que o coeficiente linear não diferiu $(\mathrm{P}<0,05)$ de zero na equação de regressão regular, comprovando a tendência do modelo em sub ou superestimar a variável avaliada (Figura 1B).

Para as vacas que consumiram além do pasto de capim coast-cross, a silagem de milho e $3 \mathrm{~kg} / \mathrm{dia}$ de concentrado, o CNCPS subestimou o consumo de matéria seca $(\mathrm{P}<0,05)$. Os elevados valores do desvio médio e do RQMEP comprovam a falta de acuidade do modelo em relação aos dados estimados (Tabela 7). 
Tabela 6 - Comparação do consumo de matéria seca estimado pelo $\mathrm{Cr}_{2} \mathrm{O}_{3}$ e predito pelo modelo CNCPS para vacas da raça Holandesa em pastagem de capim coast-cross suplementada com concentrado

\begin{tabular}{|c|c|c|c|c|}
\hline & Consumo de matéria seca (\%PV) & Desvio médio $(\% \mathrm{PV})^{3}$ & Desvio médio (\%predito) & Desvio-padrão ou RQMEP 4 \\
\hline \multicolumn{5}{|c|}{ Concentrado na quantidade de $3 \mathrm{~kg} / \mathrm{vaca}$ dia } \\
\hline $\mathrm{Cr}_{2} \mathrm{O}_{3}{ }^{1}$ & 2,47 & \multirow[t]{2}{*}{$-0,02$} & $-1,13$ & 0,25 \\
\hline $\mathrm{CNCPS}^{2}$ & 2,49 & & & 0,29 \\
\hline \multirow{3}{*}{ Regular } & \multicolumn{4}{|c|}{ Regressão ${ }^{5}$} \\
\hline & Intercepto & Inclinação & $\mathrm{R}^{2}$ & $\mathrm{P}$ \\
\hline & 1,804 & 0,266 & 0,065 & 0,011 \\
\hline \multicolumn{5}{|c|}{ Concentrado na quantidade de $6 \mathrm{~kg} / \mathrm{vaca} \times$ dia } \\
\hline $\mathrm{Cr}_{2} \mathrm{O}_{3}{ }^{1}$ & 2,64 & \multirow[t]{2}{*}{0,04} & \multirow[t]{2}{*}{1,51} & 0,57 \\
\hline \multirow[t]{3}{*}{$\mathrm{CNCPS}^{2}$} & 2,60 & & & 0,49 \\
\hline & \multicolumn{4}{|c|}{ Regressão ${ }^{5}$} \\
\hline & Intercepto & Inclinação & $\mathrm{R}^{2}$ & $\mathrm{P}$ \\
\hline Regular & 0,591 & 0,786 & 0,233 & 0,042 \\
\hline Origem 6 & - & 1,011 & 0,966 & 0,001 \\
\hline
\end{tabular}

${ }^{1}$ Consumo de matéria seca estimado por meio do método do $\mathrm{Cr}_{2} \mathrm{O}_{3} /$ DIVMS.

${ }^{2}$ Consumo de matéria seca predito pelo modelo CNCPS, versão 5.0 .

${ }^{3}$ Desvio médio = média do consumo predito pelo CNCPS menos o estimado com $\mathrm{Cr}_{2} \mathrm{O}_{3}$ /DIVMS.

${ }_{5}^{4}$ Desvio-padrão dos valores estimados $\left(\mathrm{Cr}_{2} \mathrm{O}_{3}\right)$ e raiz quadrada do quadrado médio do erro da predição (RQMEP) para os valores preditos (CNCPS).

${ }^{5}$ Os parâmetros estimados, intercepto e inclinação foram testados pelo teste $\mathrm{t}(0,05)$ para $\mathrm{B}_{0}=0$ e $\mathrm{B}_{1}=1$.

A

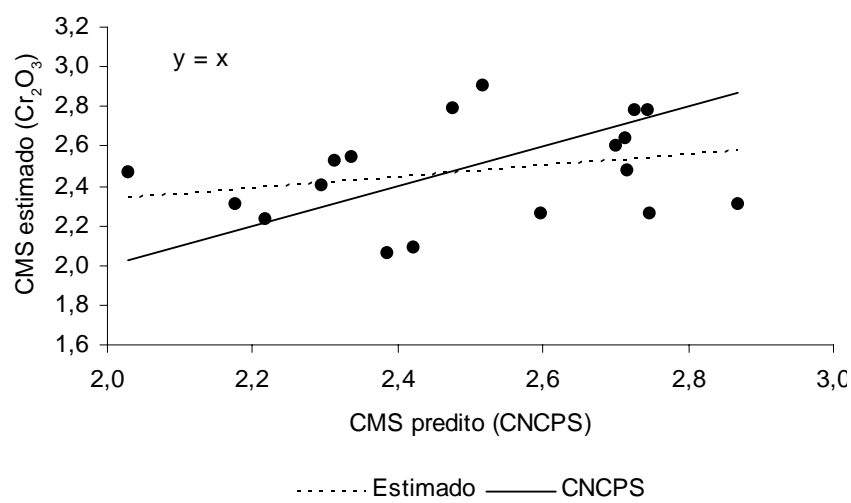

C

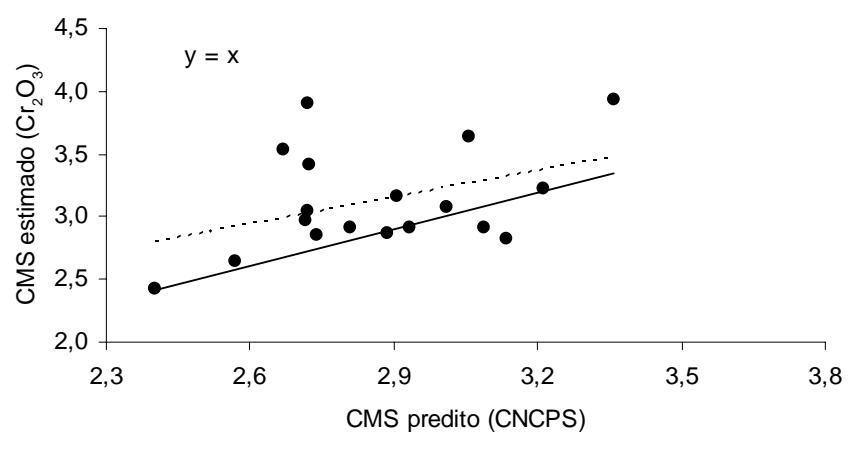

....... Estimado _ CNCPS
B

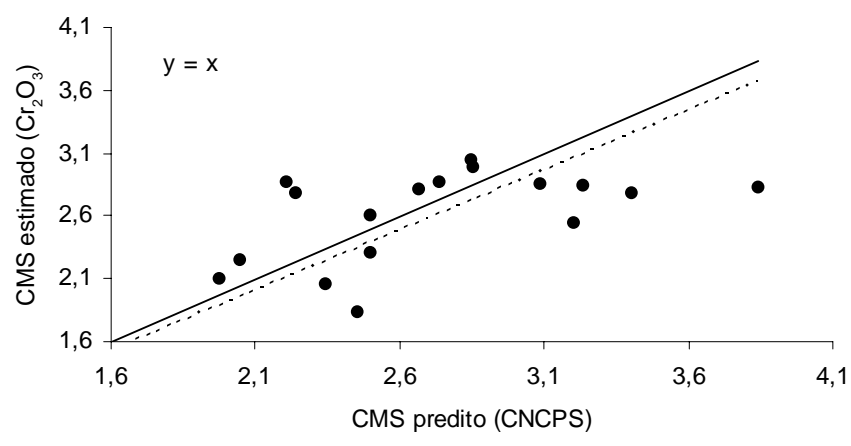

D

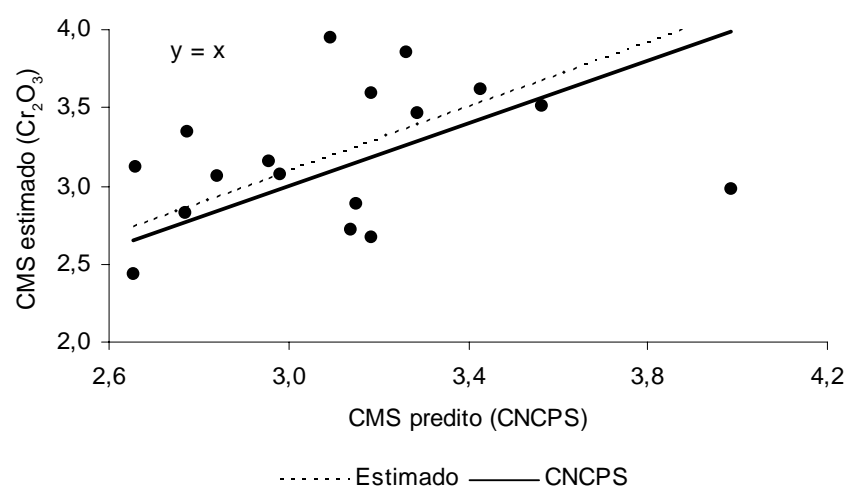

Figura 1 - Relação entre valores de consumo (\%PV) estimados pelo $\mathrm{Cr}_{2} \mathrm{O}_{3}$ /DIVMS e preditos pelo modelo CNCPS para vacas da raça Holandesa em pastagem de capim coast-cross suplementada com $3 \mathrm{~kg}$ concentrado/dia (A), $6 \mathrm{~kg}$ concentrado/dia (B), silagem de milho e $3 \mathrm{~kg}$ de concentrado/dia (C) e silagem de milho e $6 \mathrm{~kg}$ de concentrado/dia (D). 
Tabela 7 - Comparação do consumo de matéria seca estimado pelo $\mathrm{Cr}_{2} \mathrm{O}_{3}$ e predito modelo CNCPS para vacas da raça Holandesa em pastagem de capim coast-cross suplementada com silagem de milho e concentrado

\begin{tabular}{cccc}
\hline $\begin{array}{c}\text { CMS } \\
(\% \mathrm{PV})\end{array}$ & $\begin{array}{c}\text { DM } \\
(\% \mathrm{PV})^{3}\end{array}$ & $\begin{array}{c}\text { DM } \\
(\% \text { predito })\end{array}$ & $\begin{array}{c}\text { DP ou } \\
\mathrm{RQMEP}^{4}\end{array}$ \\
\hline
\end{tabular}

\begin{tabular}{lllll}
$\mathrm{Cr}_{2} \mathrm{O}_{3}{ }^{1}$ & 3,13 & 0,26 & 9,05 & 0,41 \\
$\mathrm{CNCPS}^{2}$ & 2,87 & & & 0,45 \\
\hline
\end{tabular}

\section{Regressão $0^{5}$}

\begin{tabular}{lcccc} 
& Intercepto & Inclinação & $\mathrm{R}^{2}$ & $\mathrm{P}$ \\
\hline Regular & 1,148 & 0,690 & 0,157 & 0,103 \\
Origem $^{6}$ & - & 1,078 & 0,985 & 0,001 \\
\hline \multicolumn{4}{c}{ Concentrado na quantidade de $6 \mathrm{~kg} / \mathrm{dia}$}
\end{tabular}

\begin{tabular}{lcccc}
$\mathrm{Cr}_{2} \mathrm{O}_{3}{ }^{1}$ & 3,24 & 0,11 & 3,71 & 0,46 \\
$\mathrm{CNCPS}^{2}$ & 3,12 & & & 0,47 \\
\hline & Intercepto & Inclinação & $\mathrm{R}^{2}$ & $\mathrm{P}$ \\
Regular & 1,777 & 0,468 & 0,120 & 0,157 \\
Origem $^{6}$ & - & 1,030 & 0,880 & 0,001 \\
\hline
\end{tabular}

${ }^{1}$ Consumo de matéria seca estimado por meio da metodologia do $\mathrm{Cr}_{2} \mathrm{O}_{3} /$ DIVMS.

2 Consumo de matéria seca predito pelo modelo CNCPS, versão 5.0.

${ }^{3}$ Desvio médio = média do consumo predito pelo CNCPS menos o estimado com $\mathrm{Cr}_{2} \mathrm{O}_{3}$ /DIVMS

${ }^{4}$ Desvio-padrão dos valores estimados $\left(\mathrm{Cr}_{2} \mathrm{O}_{3}\right)$ e raiz quadrada do quadrado médio do erro da predição (RQMEP) para os valores preditos (CNCPS).

${ }^{5}$ Os parâmetros estimados, intercepto e inclinação, foram testados pelo teste $\mathrm{t}$ $(0,05)$, para $\mathrm{B}_{0}=0$ e $\mathrm{B}_{1}=1$.

${ }^{6}$ Regressão passando pela origem $\left(\mathrm{B}_{0}=0\right)$.

Não houve diferença estatística $(\mathrm{P}>0,05)$ entre os valores estimados e observados para a ingestão de matéria seca dos animais que consumiram silagem de milho e $6 \mathrm{~kg}$ de concentrado (Tabela 7). A subestimativa do consumo de MS também foi descrita por Kolver et al. (1996) na avaliação do modelo CNCPS em 23 experimentos distintos, com vacas em diferentes estádios de lactação, em pastagem constituída por capim-dos-pomares (Dactylis glomerata L.), azevém (Lolium perene L.) e trevo-branco (Trifolium repens L.). Segundo os autores, o modelo subestimou o consumo de matéria seca em $11 \%$, com erro de $1,92 \mathrm{~kg} / \mathrm{dia}$ de MS e $\mathrm{R}^{2}$ de 0,80 .

Da mesma forma, Fox et al. (1992) observaram que o modelo subestimou o consumo de matéria seca em $5 \%$, com erro de $1,5 \mathrm{~kg} /$ dia de MS, principalmente quando esse consumo foi superior a $20 \mathrm{~kg} / \mathrm{dia}$ de MS. Ressalta-se que a equação utilizada pelo CNCPS para estimativa da ingestão de MS considera apenas a energia líquida de mantença $\left(E_{m}\right)$ e ignora a energia líquida de lactação $\left(E_{1}\right)$, portanto, pode ser a causa dos baixos valores preditos para o consumo em comparação aos valores obtidos pelo método $\mathrm{Cr}_{2} \mathrm{O}_{3}$ /DIVMS.
Os novos coeficientes angulares estimados evidenciam a baixa precisão do modelo na predição do consumo de matéria seca pelos animais que receberam os suplementos concentrado e silagem de milho, apresentando inclinação e trajetória diferente da reta ideal (X=Y) (Figuras 1C e 1D).

Avaliando sete experimentos com bovinos de corte, Cappelle et al. (2001) observaram que os consumos de matéria seca foram preditos corretamente pelo modelo CNCPS. Morenz (2004) avaliou o modelo na estimativa do consumo de MS de vacas Holandesa $\times$ Zebu em pastagem de capim-elefante (Pennisetum purpureum schum., cv. Napier) e verificou que o modelo estimou valor médio de consumo de $2,46 \% \mathrm{PV}$, semelhante $(\mathrm{P}<0,05)$ ao valor obtido como $\mathrm{Cr}_{2} \mathrm{O}_{3} /$ DIVMS (2,45\% PV).

Porto et al. (2006), avaliando o modelo CNCPS v.5.0 na predição do consumo de MS de vacas mestiças, observaram que os valores preditos pelo modelo foram diferentes daqueles obtidos com $\mathrm{Cr}_{2} \mathrm{O}_{3}$ /DIVMS para três forrageiras tropicais. Segundo os autores, o consumo predito pelo modelo para o capim-tanzânia (Panicum maximum Jacq.) foi de $2,65 \% \mathrm{PV}$, valor inferior ao estimado pela técnica $\mathrm{Cr}_{2} \mathrm{O}_{3}$ /DIVMS de 3,66\%PV. Os consumos de MS da gramaestrela (Cynodon nemfluensis Vanderyst) e do capimmarandu (Brachiaria brizantha Staf) foram superestimados pelo modelo, uma vez que apresentaram, respectivamente, consumos estimados de $2,67 \% \mathrm{PV}$ e $2,94 \% \mathrm{PV}$ em comparação aos obtidos com o $\mathrm{Cr}_{2} \mathrm{O}_{3}$ /DIVMS, de 2,39\%PV e 2,60\% PV, respectivamente.

Molina et al. (2004) estimaram o consumo de vacas mestiças em pastagem de $P$. maximum cv. Tobiatã consumindo $10,7 \mathrm{~kg} / \mathrm{dia}$ de MS e observaram que o modelo superestimou o consumo em $14 \%$, correspondendo a $12,2 \mathrm{~kg} / \mathrm{MS} / \mathrm{dia}$.

Segundo Morenz (2004), a avaliação do modelo, sob condições de pastejo, deve ser realizada com bastante cautela, uma vez que nestas condições o consumo real é desconhecido e só pode ser estimado por meio de metodologias que apresentem erros.

\section{Conclusões}

O Cornell Net Carbohydrate and Protein System (CNCPS) é capaz de predizer o consumo de matéria seca de vacas da raça Holandesa de forma acurada, quando comparado à metodologia do $\mathrm{Cr}_{2} \mathrm{O}_{3}$ /DIVMS, no entanto, é pouco preciso na predição dos valores estimados. Embora os dados relativos às características dos animais tenham sido informados ao programa individualmente, avaliações pontuais, com animais no mesmo estádio produtivo e reprodutivo, podem ocasionar melhor ajuste do modelo. 


\section{Literatura Citada}

ALVIM, J.M.; BOTREL, M.A.; MATins, C.E. et al. Produção de leite de vacas da raça holandesa em pastagem de coast-cross adubada com três doses de nitrogênio. In: REUNIÃO ANUAL DA SOCIEDADE BRASILEIRA DE ZOOTECNIA, 36., 1999, Porto Alegre. Anais... Porto Alegre: Sociedade Brasileira de Zootecnia, 1999. (CD-ROM).

ASSOCIATION OF OFFICIAL ANALYTICAL CHEMISTS - AOAC. Official methods of analysis. 15.ed. Arlington, Virginia, 1990. v. $1,1117 \mathrm{p}$.

CABRAL, L.S.; VALADARES FILHO, S.C.; DETMANN, E. et al. Cinética ruminal das frações de carboidratos, produção de gás, digestibilidade in vitro da matéria seca e NDT estimado da silagem de milho com diferentes proporções de grãos. Revista Brasileira Zootecnia, v.31, n.6, p.2332-2339, 2002.

CAPPELLE, E.R.; VALADARES FILHO, S.C.; COELHO DA SILVA, J.F. Estimativa do consumo e o ganho de peso de bovinos, em condições brasileiras. Revista Brasileira Zootecnia, v.30, n.6, p.1857-1865, 2001.

COCHRAN, W.G.; COX, G.M. Experimental designs. New York: Wiley, 1968. 611p

FOX, D.G.; SNIFFEN, C.J.; O'CONNOR, J.D. et al. A net carbohydrate and protein system for evaluating cattle diets. III: Cattle requirements and diet adequacy. Journal of Animal Science, v.70, n.11, p.3578-3596, 1992.

FOX, D.G.; TEDESCHI, L.O.; TYLUTKI, T.P. et al. The Cornell Net Carbohydrate and Protein System model for evaluating herd nutrition and nutrient excretion Animal Feed Science and Technology, v.112, n.1/4, p.29-78, 2004.

GENRO, T.C.M.; EUCLIDES, V.P.B.; MEDEIROS, S.R. Ingestão de matéria seca por animais em pastejo. In: REUNIÃO ANUAL DA SOCIEDADE BRASILEIRA DE ZOOTECNIA, 41., 2004, Campo Grande. Anais... Campo Grande: Sociedade Brasileira de Zootecnia, 2004. (CD-ROM).

KIMURA, F.T.; MILLER, V.L. Chromic oxide measurement. Improved determination of chromic oxide in cow feed and feces. Journal Agriculture Food Chemistry, v.5, p.216-232, 1957.

KOLVER, E.S.; BARRY, M.C.; PENNO, J.W. et al. Evaluation of the Cornell Net Carbohydrate and Protein System for dairy cows fed pasture-based diets. Proceedings of the New Zealand Society of Animal Production, v.156, p.251-254, 1996.

LAGUNES, F.I.J.; FOX, D.G.; BLAKE, R.W. et al. Evaluation of tropical grasses for milk production by dual-purpose cows in tropical Mexico. Journal of Dairy Science, v.82, n.10, p.2136-2145, 1999 .

MALAFAIA, P.A.M.; VIEIRA, R.A.M. Técnicas de determinação e avaliação dos compostos nitrogenados em alimentos para ruminantes In: SIMPÓSIO INTERNACIONAL DE DIGESTIBILIDADE EM RUMINANTES, 1997, Lavras. Anais... Lavras: UFLA-FAEPE, 1997. p.29-54.

MEISSNER, H.H.; PAULSMEIER, D.V. Plant compositional constituents affecting between-plant and animal species prediction of forage intake. Journal of Animal Science, v.73, n.8, p.2447-2457, 1995.

MERTENS, D.R. Analysis of fiber in feeds and its uses in feed evaluation and ration formulation. In: SIMPÓSIO INTERNACIONAL DE RUMINANTES, 1992, Lavras. Anais... Lavras: Sociedade Brasileira de Zootecnia, 1992. p.1-32.

MILLIGAN, R.A.; CHASE, L.E.; SNIFFEN, C.J. et al. Least-cost ration balanced dairy rations: a computer program user's manual. Ithaca: Cornell University, 1991. (Mimeo, 54).

MOLINA, D.O.; MATAMOROS, I.; ALMEIDA, Z. et al. Evaluation of the dry matter intake predictions of the Cornell Net Carbohydrate and Protein System with Holstein and dualpurpose lactating cattle in the tropics. Animal Feed Science and Technology, v.114, n.1/4, p.261-278, 2004.

MORENZ, M.J.F. Avaliação do modelo CNCPS (Cornell Net Carbohydrate and Protein System) na estimativa do consumo de matéria seca e da produção de leite de vacas mestiças em pastagem de capim-elefante (Pennisetum purpureum schum., cv. napier). 2004. 221f. Tese (Doutorado em Produção Animal) - Universidade Estadual Norte Fluminense, Campos dos Goytacases, 2004.

POND, K.R.; ELLIS, W.C.; MATIS, J.H. et al. Passage of chromium-mordanted and rare-earth-labeled fiber: time dosing kinetics. Journal of Animal Science, v.67, n.4, p.1020$1028,1989$.

PORTO, P.P.; LOPES, F.C.F.; DERESZ, F. et al. Avaliação do modelo CNCPS ("Cornell Net Carbohydrate and Protein System") na estimativa do consumo de matéria seca de vacas Holandesa $\mathrm{x}$ zebu em lactação manejadas em condição de pastejo. In: REUNIÃO ANUAL DA SOCIEDADE BRASILEIRA DE ZOOTECNIA, 43., 2006, João Pessoa. Anais... João Pessoa: Sociedade Brasileira de Zootecnia, 2006. (CD-ROM).

STATISTICAL ANALYSIS SYSTEM - SAS. SAS/STAT: user's guide version 6, 4.ed. Cary: 1991. 956p.

SNIFFEN, C.J.; O'CONNOR, J.D.; Van SOEST, P.J. et al. A net carbohydrate and protein system for evaluating cattle diets: II. Carbohydrate and protein availability. Journal of Animal Science, v.70, n.11, p.3562-3577, 1992.

TEDESCHI, L.O. Assessment of the adequacy of mathematical models. Agricultural Systems, v.89, n.2-3, p.225-247, 2006

TEDESCHI, L.O.; FOX, D.G.; RUSSEL, J.B. Accounting for the effects of a ruminal nitrogen deficiency within the structure of the Cornell Net Carbohydrate and Protein System. Journal of Animal Science, v.78, n.6, p.1648-1658, 2000.

TILLEY, J.M.A.; TERRY, R.A. A two stages technique for the "in vitro" digestion of forage crops. Journal British Grassland Society, v.18, n.1, p.104-111, 1963.

Van SOEST, P.J.; ROBERTSON, J.B. Analysis of forages and fibrous foods. A Laboratory Manual for Animal Science. Ithaca: Cornell University, 1985. 613p.

WILLIAMS, C.H.; DAVID, D.J.; IISMAA, O. The determination of chromic oxide in feces samples by atomic absorption spectrophotometry. Journal of Agriculture Science, v.59, n.3, p.381-385, 1962 . 